\title{
Measurement of sardine-generated turbulence in a large tank
}

\author{
Mamoru Tanaka ${ }^{1}$, Takeyoshi Nagai ${ }^{1}$, Tomonari Okada ${ }^{2}$, Hidekatsu Yamazaki ${ }^{1, *}$ \\ ${ }^{1}$ Faculty of Marine Science, Tokyo University of Marine Science and Technology, Minato, Tokyo 108-8477, Japan \\ ${ }^{2}$ Coastal, Marine and Disaster Prevention Department, National Institute for Land and Infrastructure Management, \\ Yokosuka, Kanagawa 239-0826, Japan
}

\begin{abstract}
While swimming organisms may cause turbulence, it is not clear how strong the turbulence is and if eddies are large enough to mix stratified water columns. We conducted an observational experiment in a large aquarium tank containing several thousand Japanese sardines Sardinops melanostictus. Turbulence data were collected from inside the sardine school using a turbulence microstructure profiler. The averaged turbulent kinetic energy dissipation rate was $2.3 \times 10^{-4} \mathrm{~W} \mathrm{~kg}^{-1}$ inside the school, while the averaged background value was $6.7 \times 10^{-6} \mathrm{~W} \mathrm{~kg}^{-1}$. The school displayed fast and non-continuous 'avoidance behavior', or fast and long-lasting 'feeding behavior' during the measurements. A noticeable difference between the 2 behaviors was found in turbulent shear spectra: the avoidance behavior spectra showed a power decline in comparison with the Nasmyth empirical spectrum in the inertial sub-range, but the feeding behavior spectra exhibited no power decline, even in the inertial sub-range. In the latter case, the sardine school imparted kinetic energy into scales larger than the average individual body size of $0.173 \mathrm{~m}$. This result is a counter-example to a general hypothesis that swimming organisms cannot impart kinetic energy at scales larger than their individual body size.
\end{abstract}

KEY WORDS: Biomixing $\cdot$ Sardinops melanostictus $\cdot$ Aquarium experiment $\cdot$ Turbulent mixing

\section{INTRODUCTION}

Mixing due to swimming marine organisms (hereinafter biomixing) is a poorly understood phenomenon. Although major energy sources that drive the global ocean general circulation, such as tides and winds, have been relatively well quantified, contributions from biomixing have been elusive (Ferrari \& Wunsch 2009). Nevertheless, some studies (Dewar et al. 2006) have reported that biomixing could possibly be an important component for the global energy budget of ocean general circulation. Dewar et al. (2006) have estimated that $1 \%$ of the total chemical power stored in marine organisms, $62.7 \mathrm{TW}$, could be converted into mechanical energy of the ocean. This is comparable to the power input from winds and

\footnotetext{
*Corresponding author: hide@kaiyodai.ac.jp
}

tides (Ferrari \& Wunsch 2009). In addition, Huntley \& Zhou (2004) estimated that schools and swarms of organisms swimming at their moderate speeds can produce strong turbulence equivalent to a rate of kinetic energy dissipation of $10^{-5} \mathrm{~W} \mathrm{~kg}^{-1}$, regardless of body size (from zooplankton to cetaceans). This value is comparable to the energy dissipation rates measured in well-mixed surface layers (Thorpe 2007). The estimates shown above imply the importance of biomixing in ocean mixing, and consequently, in driving the ocean general circulation.

Besides the theoretical estimates of Dewar et al. (2006) and Huntley \& Zhou (2004), observational evidence of biomixing has been reported. Kunze et al. (2006) measured high turbulent kinetic energy dissipation rates of $10^{-5}$ to $10^{-4} \mathrm{~W} \mathrm{~kg}^{-1}$ in layers with high

() The authors 2017. Open Access under Creative Commons by Attribution Licence. Use, distribution and reproduction are unrestricted. Authors and original publication must be credited. 
acoustic backscatter intensity, mainly due to krill, observed by an echo sounder in Saanich Inlet, BC, Canada. Gregg \& Horne (2009) also measured elevated turbulent kinetic energy dissipation rates of $10^{-6}$ to $10^{-5} \mathrm{~W} \mathrm{~kg}^{-1}$ compared to the background value of $10^{-9} \mathrm{~W} \mathrm{~kg}^{-1}$ with high acoustic backscatter intensity in Monterey Bay, CA, USA, and surmised that the constituents of the high acoustic intensity were anchovy schools, based on the acoustic signals. These measured turbulent kinetic energy dissipation rates are comparable to the theoretical value of $10^{-5} \mathrm{~W} \mathrm{~kg}^{-1}$ estimated by Huntley \& Zhou (2004).

However, there are a number of reports which contradict the studies that suggest the importance of biomixing. From additional field observations of biomixing in Saanich Inlet, Rousseau et al. (2010) reported turbulent kinetic energy dissipation rates of $10^{-8} \mathrm{~W} \mathrm{~kg}^{-1}$ with high acoustic backscatter intensity, a dissipation rate higher by a factor of 2 than that in acoustically quiet waters, but 3 orders of magnitude lower than the theoretical $10^{-5} \mathrm{~W} \mathrm{~kg}^{-1}$ estimated by Huntley \& Zhou (2004). Sato et al. (2014) reported no correlation between turbulent kinetic energy dissipation rates and volume backscattering strength in Saanich Inlet. On the other hand, Ross \& Lueck (2005) developed an inverse method to estimate turbulence intensity $\left(10^{-8}\right.$ to $\left.10^{-3} \mathrm{~W} \mathrm{~kg}^{-1}\right)$ from volume backscattering strength in a stratified and highly turbulent water column. Even if marine organisms can induce strong turbulence, it does not always mean strong turbulent 'mixing'. Visser (2007) pointed out that small swimmers, such as krill $(\sim 1 \mathrm{~cm})$, cannot produce eddies and subsequent density inversions larger than their body size, implying that biomixing by small swimmers is less efficient than physically induced turbulence. Based on krill body size $(1 \mathrm{~cm})$, Visser estimated that, at most, $1 \%$ of the total kinetic energy produced by krill swimming is used in mixing, while it is up to $20 \%$ for physically induced turbulence (Osborn 1980). Using in situ observation data, Gregg \& Horne (2009) reported that mixing inside fish schools was 100 times less efficient for vertical mixing of density-stratified water than that due to physically induced turbulence, consistent with Visser (2007). In contrast, based on field campaigns with turbulence measurements, net samplings, still image recordings and acoustic surveys, Lorke \& Probst (2010) found that, regardless of whether turbulence was measured inside or outside of fish schools, roughly $20 \%$ of the turbulent kinetic energy was used for vertical mixing of density. Katija \& Dabiri (2009) pointed out that fluid viscosity and body shapes, rather than generated eddy size, are important in determining the efficiency of swimming-induced mixing, as the viscous fluids can be drifted along the swimming organisms, and that more efficient swimmers are more efficient in drifting fluid around their bodies: the length of drifted water along the streamline, not the body length, is the important scale. The studies discussed above, with conflicting conclusions regarding the efficiency of biomixing, clearly demonstrate the need for further studies.

One of the most problematic issues in the previous studies is that one cannot be sure whether the measured turbulence was caused by the swimming organisms, and that it is not possible to know the detailed swimming behaviors of the organisms when they encountered the instruments just by using echo sounders, which were frequently utilized in the studies. Characteristics such as swimming behavior, swimming speed and synchrony of group motion can be influenced by the presence of instruments (e.g. avoidance of an approaching turbulence microstructure profiler). Although these characteristics appear to be critical for determining the intensity of the induced turbulence (Huntley \& Zhou 2004), the previous observations did not consider swimming behavior but used acoustic backscatter merely to estimate population density. However, in a tank experiment, Catton et al. (2011) reported that individual (not aggregated) krill were able to transfer a water parcel by a distance of 1 body length, while aggregated krill actively transferred water parcels down to successive group members and disturbed the water column at a scale of aggregations. They suggested that different biological characteristics (i.e. individual or aggregation, distance between group members) result in different fluid motions around the swimming organism. Thus, obtaining turbulence measurements simultaneously with visual observations of organism aggregations and their swimming behavior is necessary to investigate the intensity of turbulence generated by an organism and to elucidate whether the generated turbulent eddy is large enough to produce mixing in the ocean.

In this study, we conducted an experiment in a large aquarium tank containing several thousand Japanese sardines Sardinops melanostictus to measure turbulence inside the sardine school and to observe the school characteristics simultaneously. The objectives of this study were to measure biologically induced turbulence and to investigate the relationship between turbulent properties and school characteristics. 


\section{MATERIALS AND METHODS}

\section{Microstructure profiler and deployment}

A microstructure profiler, the Turbulence Ocean Microstructure Acquisition Profiler-9 (Fig. 1A; hereinafter TM9; JFE Advantech), was used to measure turbulence inside the sardine school. The $1.3 \mathrm{~m}$ long free-ascending TM9 sampled data from the bottom of the experiment tank until it reached the surface without any interruptions (Figs. 1B \& 2). Nominal ascending speed was roughly $0.5 \mathrm{~m} \mathrm{~s}^{-1}$. In a past study, the TM9 was deployed in a small bay as shallow as $20 \mathrm{~m}$ depth (Saita et al. 2009). The TM9 had 2 turbulent shear probes (hereinafter shear-1 and shear-2; digitized at $512 \mathrm{~Hz}$ ), an FP07 fast temperature probe $(512 \mathrm{~Hz})$, a light-emitting diode fluorescence/turbidity probe $(256 \mathrm{~Hz})$, a CTD $(64 \mathrm{~Hz})$ and XYZ 3-directional accelerometers $(256 \mathrm{~Hz})$ on the head. Previous studies (Kunze et al. 2006, Gregg \& Horne 2009, Rousseau et al. 2010) used free-fall microstructure profilers, which may not be suited to measure turbulence near the water surface due to unstable motion of the profiler's body. In order to maximize the sampling water column, we employed a free-ascending profiler.
For deployment, a weighted releaser was attached to the tail of the TM9. After the TM9 had sunk to the bottom, we waited $3 \mathrm{~min}$ before releasing the attached weight in order to avoid contamination from disturbances generated by the instrument setup. Eight deployments were performed during the course of the experiment (Table 1).

\section{Experimental tank and sardines}

We used a large indoor tank (Fig. 1B) at an aquarium (Yokohama Hakkeijima Sea Paradise, www. seaparadise.co.jp/english/). Since the tank is managed as part of a commercial aquarium, we had a limited time window and were allowed to deploy the instrument only 8 times. The $7 \mathrm{~m}$ deep tank held $1500 \mathrm{~m}^{3}$ of seawater and contained roughly 5000 Japanese sardines Sardinops melanostictus, caught in the sea around Japan. Body length of the sardines, $L$, was measured as total length after the experiment, and averaged $0.173 \mathrm{~m}(\mathrm{n}=35$; Table 2$)$, typical of adult Japanese sardines (Whitehead 1985). The tank also contained predators of sardines, such as sand tiger sharks, rays and mackerels. Due to their presence, the sardines regularly formed an aggregation,
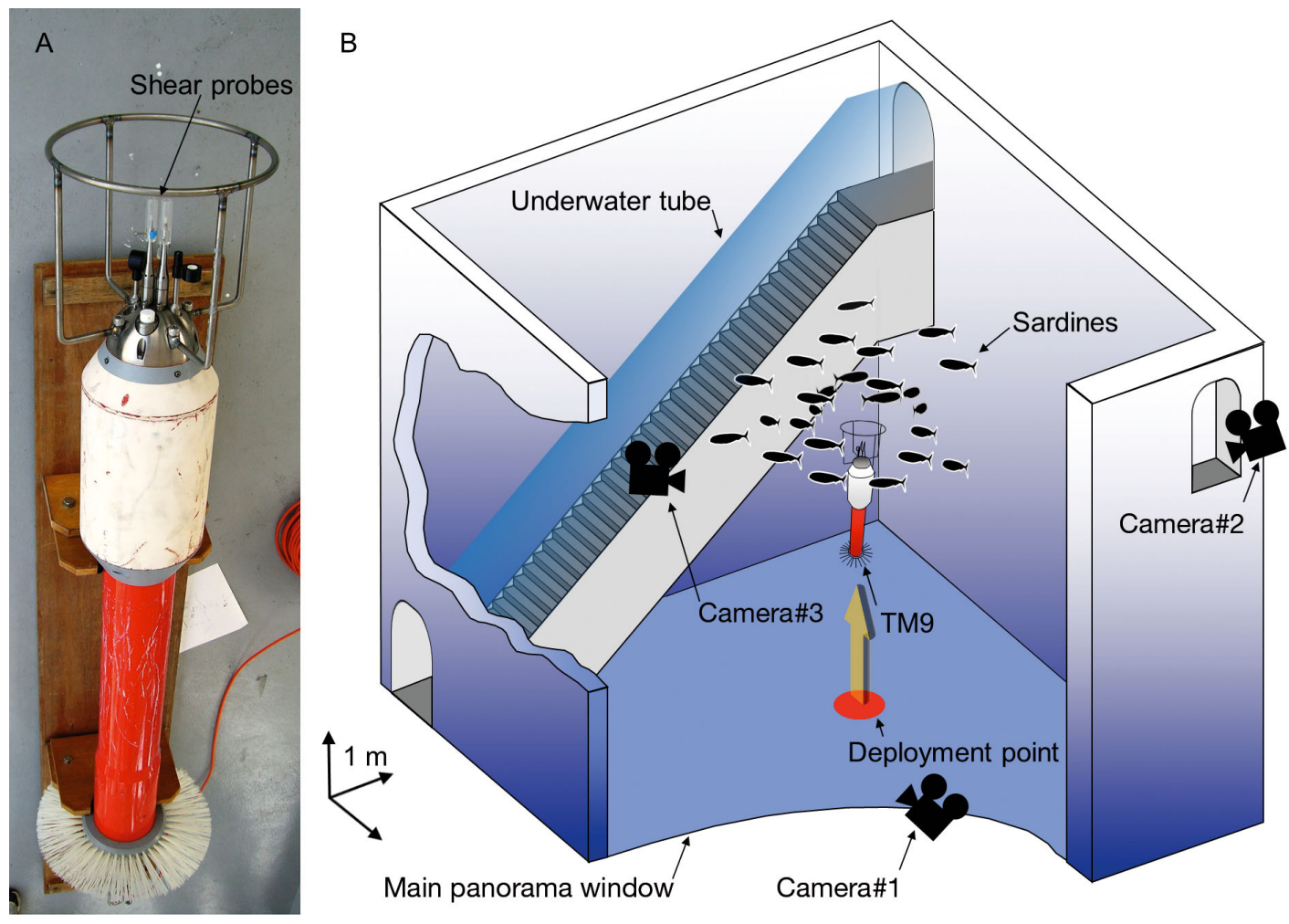

Fig. 1. (A) Microstructure profiler, Turbulence Ocean Microstructure Acquisition Profiler-9 (TM9). (B) Experimental setup. Approximate scale shown at lower left 


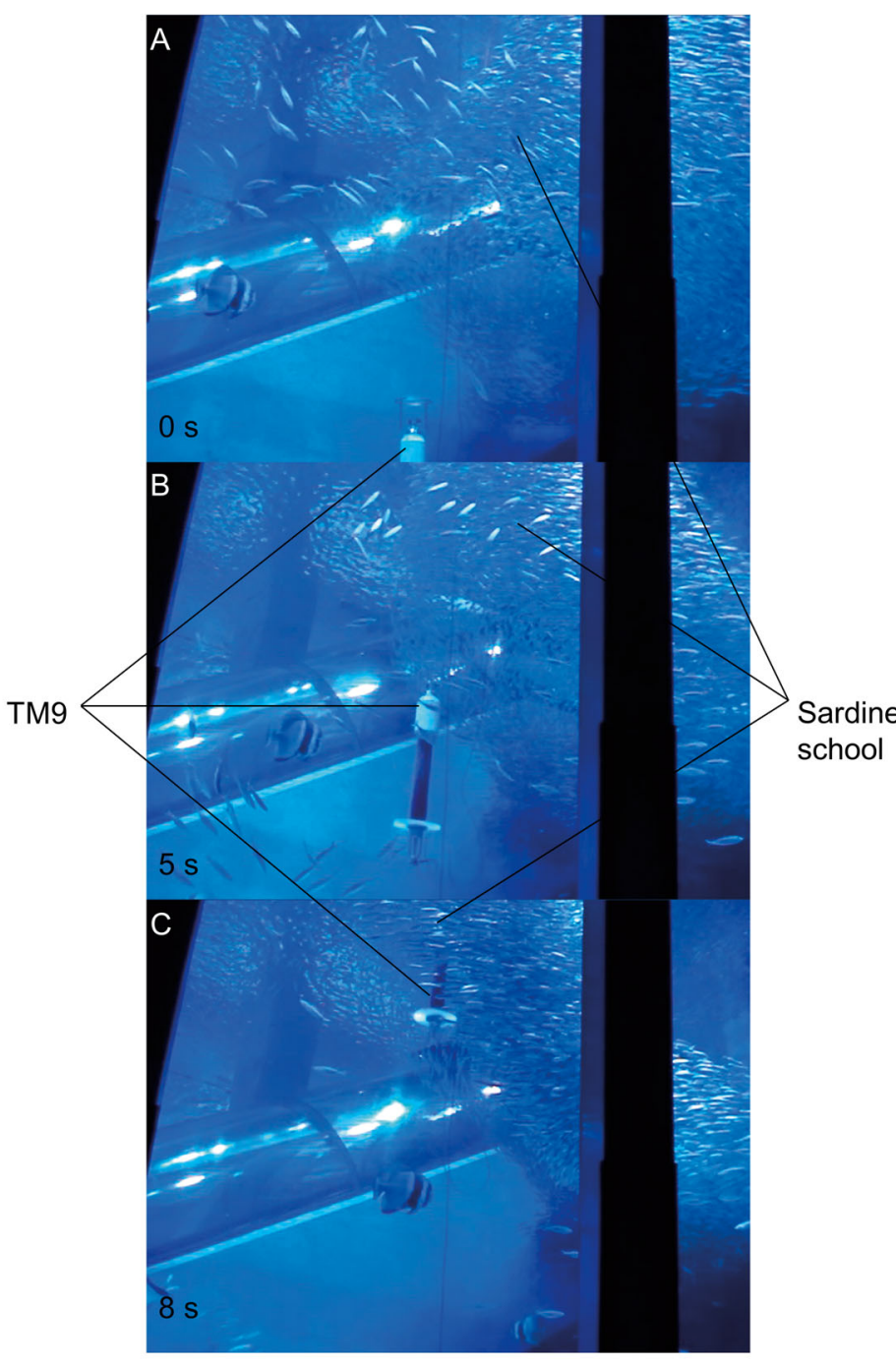

Fig. 2. Still images from video footage taken during Deployment 1 by Camera \#1. (A) Sardines forming a school above the TM9 microstructure profiler prior to release. (B) TM9 ascending toward sardine school. (C) TM9 measuring turbulence inside the sardine school. Approximate times elapsed from release of TM9 shown in bottom left of each image

Table 2. Body dimensions and wet weight of sardines kept in the tank during measurements

\begin{tabular}{|lcc|}
\hline Measured item & Mean & SD \\
\hline Length $(\mathrm{m})$ & 0.173 & 0.015 \\
Width $(\mathrm{m})$ & 0.018 & 0.002 \\
Height $(\mathrm{m})$ & 0.029 & 0.002 \\
Wet weight $(\mathrm{kg})$ & 0.033 & 0.008 \\
\hline
\end{tabular}

or school, during the measurements. Since predator abundance was relatively low compared to that of the sardines (e.g. a few sand tiger sharks and rays, and several tens of mackerels) and no predators were identified near the measuring sensors, turbulence generation due to the predators was ignored.

Water temperature and salinity in the tank were $20.0 \pm 0.016^{\circ} \mathrm{C}$ (mean $\pm \mathrm{SD}$ ) and $30.6 \pm 0.001$ respectively. Mean and SD were calculated from all deployments of the TM9. The water column was almost homogeneous, with very weak stratification dominated by temperature. The spatial- and temporalaveraged stratification corresponded to a buoyancy frequency of $N=1.6 \times 10^{-3} \mathrm{~s}^{-1}$, comparable to that in the surface mixed layer of the ocean (Thorpe 2007).

Table 1. Deployments of the TM9 microstructure profiler. Presence: whether or not deployment was successful in measuring inside the sardine school. Period: amount of time taken for the TM9 to measure inside the sardine school (highlighted in light gray in Fig. 3). Depth: vertical distance measured by the TM9 inside the sardine school. Thickness: sardine school thickness along vertical coordinate. $(\bar{\varepsilon})$ : energy dissipation rate averaged over the period. Background $\bar{\varepsilon}$ : energy dissipation rate averaged over the calculation sections outside the sardine school

\begin{tabular}{|c|c|c|c|c|c|c|c|c|}
\hline \multirow{2}{*}{ Deployment } & \multirow{2}{*}{$\begin{array}{l}\text { Launch } \\
\text { time }\end{array}$} & \multicolumn{6}{|c|}{ - Sardine school - } & \multirow{2}{*}{$\begin{array}{c}\text { Background } \bar{\varepsilon} \\
\left(\times 10^{-6} \mathrm{~W} \mathrm{~kg}^{-1}\right)\end{array}$} \\
\hline & & Presence & $\begin{array}{l}\text { Period } \\
\text { (s) }\end{array}$ & $\begin{array}{l}\text { Depth } \\
\text { (m) }\end{array}$ & $\begin{array}{l}\text { Thickness } \\
\text { (m) }\end{array}$ & Behavior & $\begin{array}{c}(\bar{\varepsilon}) \\
\left(\mathrm{W} \mathrm{kg}^{-1}\right)\end{array}$ & \\
\hline 1 & $19: 33$ & Yes & $3-9$ & $0.5-3.6$ & 3.1 & Avoidance & $3.2 \times 10^{-4}$ & 6.2 \\
\hline 2 & $19: 54$ & Yes & $0-2$ & $3.0-3.9$ & 0.9 & Avoidance & $8.6 \times 10^{-5}$ & 5.9 \\
\hline 3 & $19: 59$ & Yes & $6-8$ & $0.5-1.6$ & 1.1 & Feeding & $2.2 \times 10^{-4}$ & 3.1 \\
\hline 4 & $20: 02$ & Yes & $4-7$ & $0.5-2.1$ & 1.6 & Avoidance & $8.7 \times 10^{-5}$ & 5.1 \\
\hline $5^{\mathrm{a}}$ & $19: 45$ & No & - & - & - & - & - & 9.7 \\
\hline 6 & $20: 07$ & No & - & - & - & - & - & 8.1 \\
\hline 7 & $20: 10$ & No & - & - & - & - & - & 4.9 \\
\hline 8 & $20: 21$ & No & - & - & - & - & - & 4.1 \\
\hline
\end{tabular}


Aeration devices that created bubble columns and circulation to stir the water were turned off $1 \mathrm{~h}$ before commencing the experiment to minimize turbulence generated from the circulation system.

In order to visually inspect the performance of the TM9, 3 video cameras were placed around the tank (Figs. 1B \& 2): Camera \#1 in front of the panorama window, Camera \#2 in front of an acrylic glass window located $6 \mathrm{~m}$ above the bottom, and Camera \#3 in an underwater tube. Cameras \#1 and 2 were mounted on tripods and Camera \#3 was hand-held. Footage was recorded simultaneously by all 3 video cameras.

Based on the film footage, we distinguished 3 different types of swimming behavior of the sardine school: avoidance, feeding, and cruising behaviors. Given that the turbulence sensors (i.e. the shear probes) require a background flow to measure turbulence, and thus the TM9 needed to ascend in the tank, it was not possible to suppress the sardines' avoidance behavior in response to the TM9, which was measuring turbulence inside the school. All of the turbulence measurements inside the school were made when the sardines showed avoidance behavior. However, when aquarium personnel fed food pellets ( $2 \mathrm{~mm}$ in diameter) to the sardines before the launch of Deployment 3, and the sardines were feeding on the pellets, they exhibited a different swimming pattern (feeding behavior) from avoidance behavior shown in the other deployments. Avoidance behavior was short-burst swimming; on the other hand, feeding behavior was comparatively fast and long-lasting swimming. The school displayed cruising behavior when neither avoidance nor feeding behavior was exhibited. Thus, no turbulence measurement from cruising behavior was obtained.

For each behavior, we were able to measure swimming speeds relative to $L$ from the footage. Relative speeds were used to estimate absolute swimming speeds, assuming $L=0.173 \mathrm{~m}$. Swimming behavior is described in 'Results: School behavior' and discussed in 'Discussion: Swimming behavior'.

For packing density of the sardines in the school, we tried to estimate this using video footage obtained from the 3 video cameras. However, packing density was hard to quantify from the footage since the arrangement of the video cameras was not suited to establish the 3-dimensional position of each sardine. Therefore, we estimated packing density by making use of the measured body length of the sardines and assuming that the distribution of the sardines in the school displayed hexagonal close-packing of equal spheres, as discussed in 'Discussion: Dissipation rates'.

\section{Turbulent kinetic energy dissipation rate}

Assuming isotropy of turbulence, the rate of turbulent kinetic energy dissipation, $\varepsilon$ is estimated as

$$
\varepsilon=\frac{15}{2} \cdot v \cdot \overline{\left(\frac{\partial u}{\partial z}\right)^{2}}=\frac{15}{2} \cdot v \cdot \int_{k_{1}}^{k_{2}} \phi(k) \mathrm{d} k
$$

where $v$ is the kinematic viscosity, the overbar indicates the temporal average, $\partial u / \partial z$ is the velocity vertical shear, $k$ is the wavenumber, $\phi$ is the shear spectrum as a function of $k_{1}$ and $k_{1}$ and $k_{2}$ are the integration range. In this study, $k_{1}=1$ cycles per meter (cpm) and $k_{2}=k_{\eta} / 2$, where $k_{\eta}$ is the Kolmogorov wavenumber, $k_{\eta}=\left(\varepsilon \cdot v^{-3}\right)^{1 / 4}$. When $k_{2}$ was larger than the Nyquist wavenumber $(\sim 500 \mathrm{cpm}$ in this study), $\phi$ was extrapolated to $k_{2}$ by using the Nasmyth empirical spectrum (Oakey 1982), which is an empirical spectrum for a well-developed turbulence field. Wavenumber ranges, excluding highfrequency noises from the system electronics, were extrapolated by the Nasmyth spectrum for the integration in Eq. (1). The logarithmic spectral power loss along increasing wavenumbers, which depends on the size of the sensing tips of the turbulent shear probes $(\sim 1 \mathrm{~cm})$, was corrected using a single pole filter (Oakey 1982). The rate of kinetic energy dissipation was estimated from a $2 \mathrm{~s}$ section of data which was half-overlapped with the next sections. From the video footage, we were able to visually distinguish whether or not the estimated $\varepsilon$ values were acquired inside the sardine school by measuring the distance between the school and the turbulent shear probes.

\section{RESULTS}

\section{School behavior}

Deployments 1 to 4 passed inside the sardine school. Except for Deployment 3, the sardine school avoided the oncoming TM9 by dispersing in different directions. For each deployment, the distance between the school and the TM9 was about $1 \mathrm{~m}$. The swimming speed of this avoidance behavior was $V_{\text {avoidance }}=1.08 \pm 0.11 \mathrm{~m} \mathrm{~s}^{-1}($ mean $\pm \mathrm{SD}, \mathrm{n}=7$ ), estimated from Deployment 2 footage. Predator avoidance (i.e. ray) was observed as well. Swimming speed during avoidance behavior (away from the predator) was $1.32 \pm 0.18 \mathrm{~m} \mathrm{~s}^{-1}$, estimated from footage taken before Deployment 1 , and the estimated distance between the rear of the school and the predator was about $1 \mathrm{~m}$. On the other hand, when sardines were fed $20 \mathrm{~s}$ before the launch of 
Deployment 3, the school swam relatively quickly $\left(V_{\text {feeding }}=0.72 \pm 0.09 \mathrm{~m} \mathrm{~s}^{-1} ; \mathrm{n}=7\right.$ ) in the same direction. When the TM9 was ascending into the school, sardines avoided the instrument, keeping a distance of $\sim 1 \mathrm{~m}$ from it without changing their swimming speed; this response was not as prominent as in avoidance behavior, and was categorized as feeding behavior. During feeding behavior, sardines appeared to be more focused on the food than on the approaching TM9. Except when expressing avoidance or feeding behavior, the sardine school swam at a relatively slow speed, categorized as cruising behavior, at a rate of $v_{\text {cruising }}=0.26 \pm 0.04 \mathrm{~m} \mathrm{~s}^{-1}$ ( $\mathrm{n}=$ 10), estimated from footage taken before Deployment 1. For any behavior, the sardines kept synchrony with regard to their swimming speed, duration, and timing when they changed from one behavior to another. Deployments 5 to 8 passed outside of the sardine school.
Predators did not affect school behavior during any deployments, and the spatial distance between the predators and the TM9 was significantly large for each deployment. No physical contact between the sardines and the turbulent shear probes was observed. Thus all turbulence signals inside the school recorded by the TM9 were due to sardine swimming.

\section{Turbulence inside and outside sardine school}

Based on TM9 data obtained outside the sardine school (Deployments 5 to 8), the range of background energy dissipation rates was $\varepsilon=10^{-6}$ to $10^{-5} \mathrm{~W} \mathrm{~kg}^{-1}$ (Fig. 3E-H). The average was $\varepsilon=6.7 \times 10^{-6} \mathrm{~W} \mathrm{~kg}^{-1}$. Maximum $\varepsilon$ was roughly $10^{-5} \mathrm{~W} \mathrm{~kg}^{-1}$ and minimum $\varepsilon$ was $1.1 \times 10^{-6} \mathrm{~W} \mathrm{~kg}^{-1}$. This background turbulence level is similar to that found in the surface mixed layer of the ocean (Thorpe 2007).

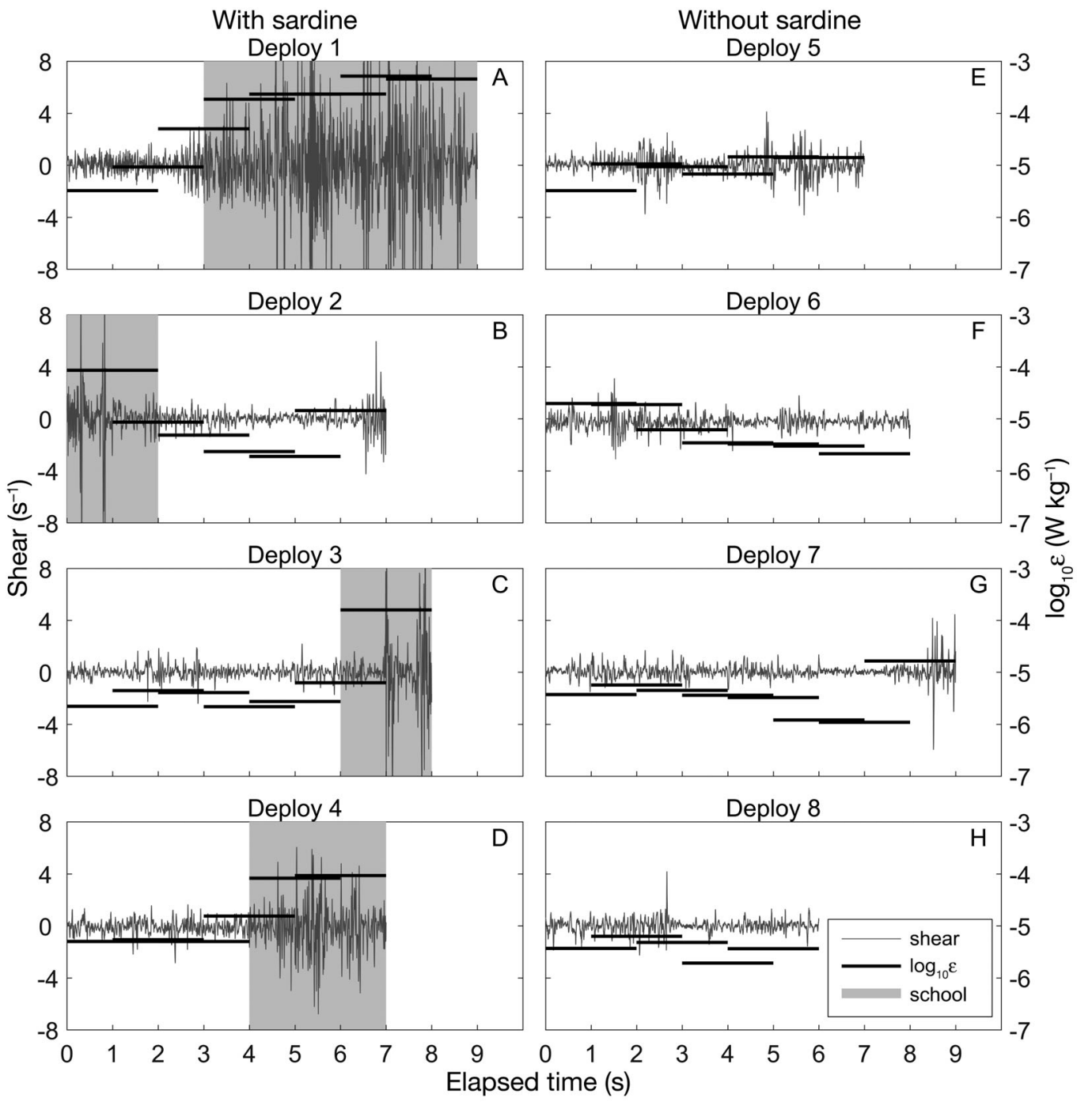

Fig. 3. Time series of turbulent velocity shear (thin gray lines) and kinetic energy dissipation rates $\varepsilon$ (thick black bars) for 8 deployments (deploy) of the TM9 microstructure profiler. Widths of black bars (2 s) indicate sections used to estimate $\varepsilon$. Data from (A-D) inside and (E-H) outside the sardine (Sardinops melanostictus) school. Light gray sections in (A-D) show when the TM9 acquired data from inside the school 
Inside the sardine school, $\varepsilon$ values exceeded $10^{-4} \mathrm{~W}$ $\mathrm{kg}^{-1}$ (Fig. 3A-D, Table 1). The average was $2.3 \times 10^{-4}$ $\mathrm{W} \mathrm{kg}^{-1}$, roughly 50 times greater than the background value. There was no significant difference in the magnitude of $\varepsilon$ between the avoidance and feeding behaviors (Table 1).

\section{Spectrum analysis}

In order to consider the properties of turbulence induced by the sardine school, we examined the wavenumber spectra of turbulent velocity shear. Because mean $L$ was $0.173 \mathrm{~m}$, the wavenumber $k=L^{-1}=5.8 \mathrm{cpm}$ is considered to be representative for that size.

Shear spectra measured outside the sardine school followed the Nasmyth spectrum, as in physically induced turbulence in the ocean (Fig. 4). The Nasmyth spectrum was within or close to the upper and lower $95 \%$ confidence intervals of the measured shear spectra.

Shear spectra obtained from the data inside the school during avoidance behavior did not follow the Nasmyth spectrum well (Fig. 5). For example, in the case of Deployment 1 , the spectrum had a slope of $k^{1}$ in 1-20 cpm, while the Nasmyth spectrum has a slope of $k^{1 / 3}$ in the inertial sub-range (Fig. 5A). Spectral power at $20-40 \mathrm{cpm}$ was higher than that of the Nasmyth spectrum, while spectral power in the wavenumber ranges lower than $L^{-1}=5.8 \mathrm{cpm}$ was significantly lower than the Nasmyth spectrum (Fig. 5A). Spectra computed from Deployment 2 and Deployment 4 data, inside the sardine school, had power declines in the inertial sub-range similar to

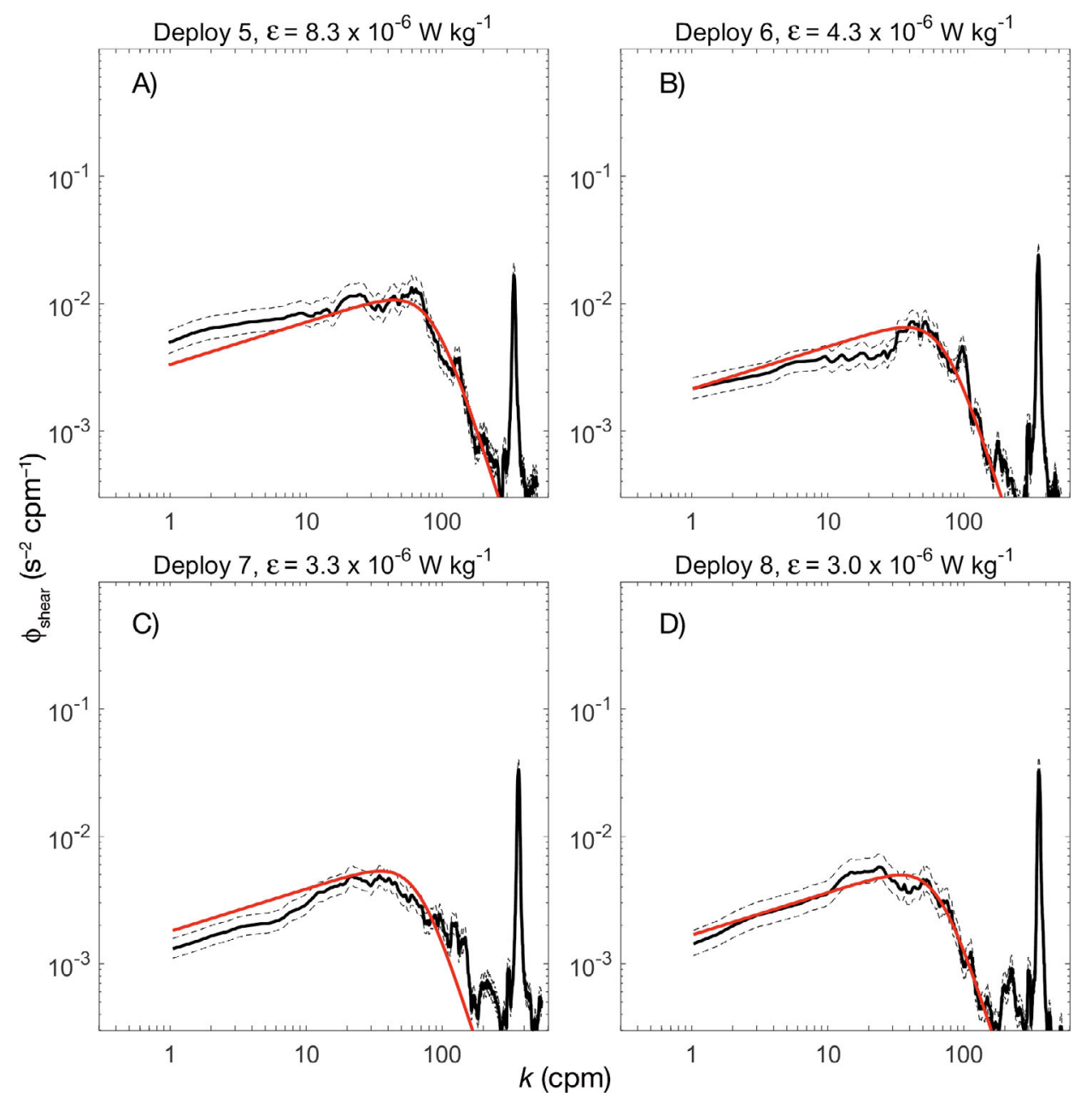

Fig. 4. Spectra $(\phi)$ of turbulent velocity shear outside the sardine school for (A-D) Deployments 5 to 8 , respectively, as functions of wavenumber $k$ (cycles per meter, cpm). Measured spectra denoted by thick black lines, upper and lower $95 \%$ CIs by thin dashed lines, and Nasmyth spectrum by thick red lines. Each Nasmyth spectrum corresponds to the turbulent kinetic energy dissipation rates $\left(\varepsilon, \mathrm{W} \mathrm{kg}^{-1}\right)$ above the panels. Peaks at around $k=300 \mathrm{cpm}$ caused by instrument's electrical noise 

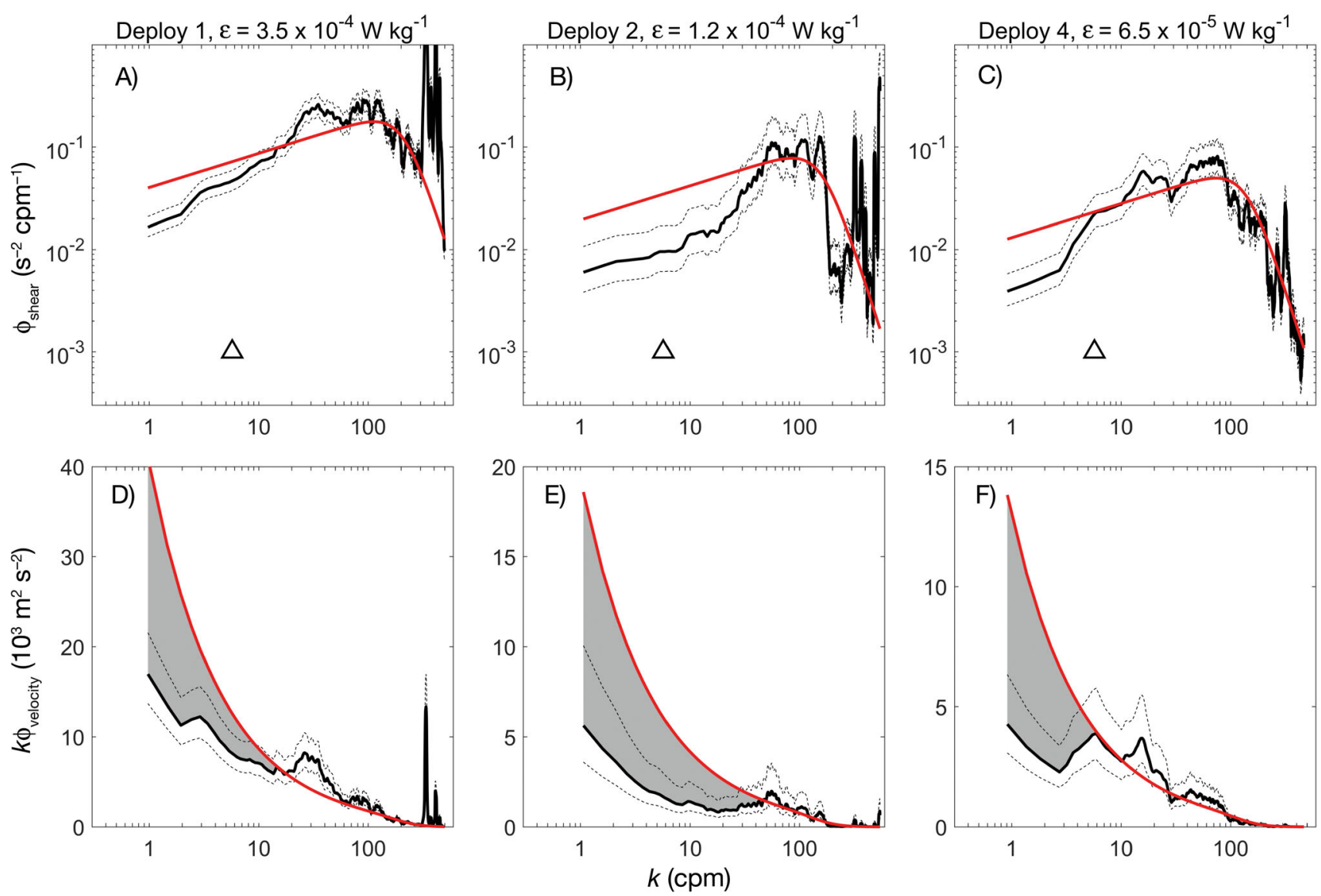

Fig. 5. (A-C) Spectra $(\phi)$ of turbulent velocity shear inside the sardine school displaying avoidance behavior for Deployments (A) 1, (B) 2, and (C) 4. Line descriptions same as in Fig. 4. Inverse of the average body length $L^{-1}=5.8 \mathrm{cpm}(L=0.173 \mathrm{~m}) \mathrm{shown}$ as a triangle. (D-F) Variance-preserving forms of velocity spectra corresponding to (A-C). Areas where velocity spectra are lower than Nasmyth spectrum highlighted in light gray. See Fig. 4 for further details

Deployment 1 (Fig. 5B,C). For these spectra, the spectral power at $1 \mathrm{cpm}$ was about one-third that of the Nasmyth spectrum regardless of the magnitude of $\varepsilon$, which is clearly shown by the variance-preserving forms of the velocity spectra corresponding to each shear spectrum (Fig. 5D-F).

On the other hand, shear spectra measured inside the sardine school while the sardines were fed show relatively good agreement with the Nasmyth spectrum in the wavenumber ranges lower than $L^{-1}$ (Fig. 6). The shear spectra computed using shear-1 and shear-2 had power levels comparable to that of the Nasmyth spectrum in the wavenumber ranges lower than $L^{-1}$ (Fig. 6A,B). However, the spectral shapes are somewhat distorted from the Nasmyth spectrum, with convex down and up at the transition between inertial sub-range and viscous sub-range, probably reflecting the high spatial and temporal variabilities in turbulence generated by the sardine school.
All non-dimensionalized spectra and their averaged spectra are shown separately for the turbulence induced by avoidance behavior (Fig. 7A,C) and that induced by feeding behavior (Fig. 7B,D). Turbulence induced by avoidance behavior had a power decline in the inertial sub-range on average, while that induced by feeding behavior showed no power decline.

\section{DISCUSSION}

\section{Swimming behavior}

Turbulence was measured inside the sardine school displaying either avoidance or feeding behavior, but turbulence during cruising behavior was not measurable. Few studies have reported in situ swimming speed of sardines: 0.21 to $0.77 \mathrm{~m} \mathrm{~s}^{-1}$ from Hara (1987) and 0.67 to $1.59 \mathrm{~m} \mathrm{~s}^{-1}$ from Misund et al. (2003). Swimming speeds observed in the present 

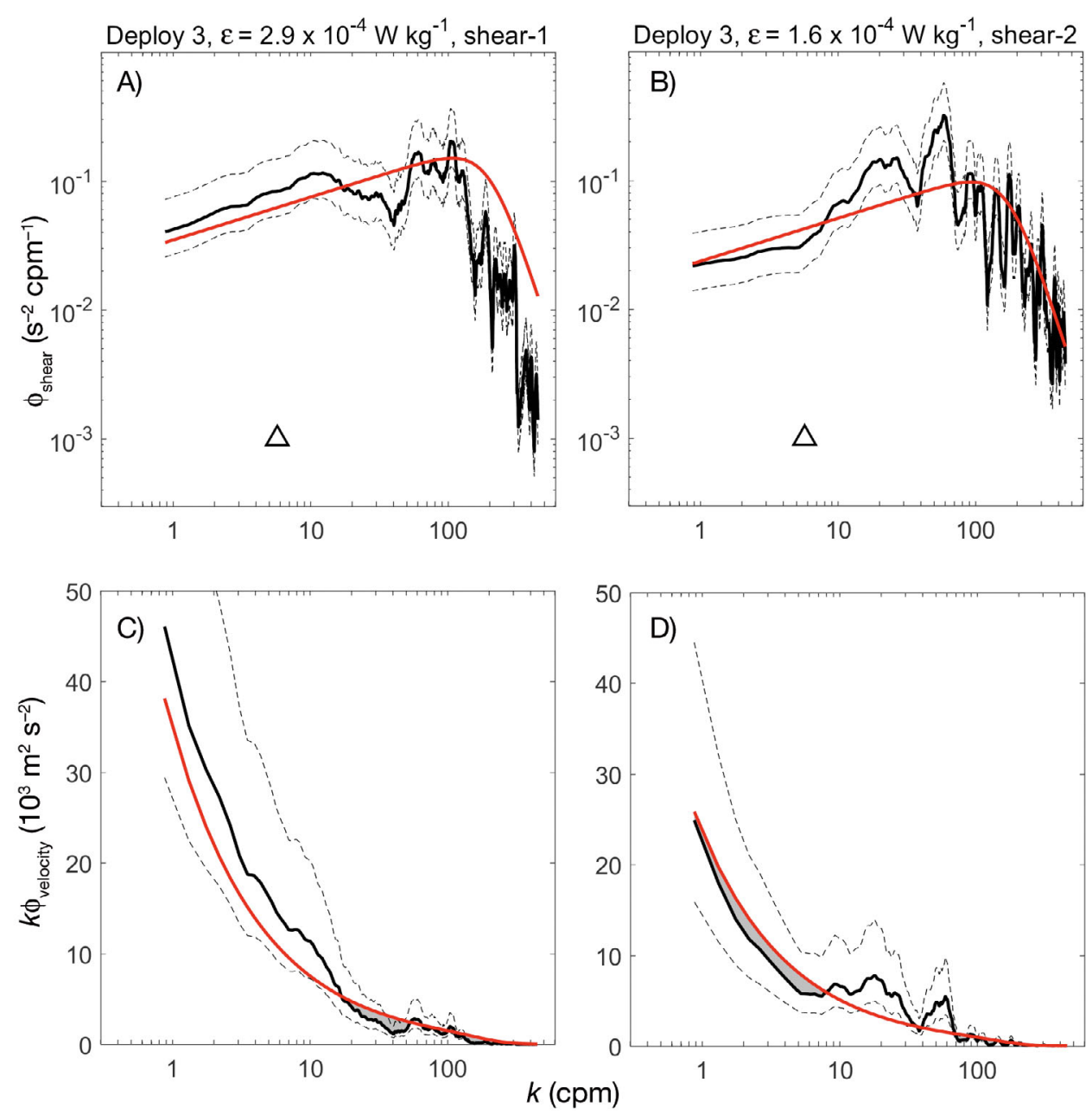

Fig. 6. Same as Fig. 5, but with spectra acquired inside the sardine school during feeding behavior in Deployment 3. (A,C) Shear-1 and (B,D) shear-2 probes. See Figs. 4 \& 5 for further details

study during 3 types of behavior were $V_{\text {avoidance }}=1.08$ $\pm 0.11 \mathrm{~m} \mathrm{~s}^{-1}, V_{\text {feeding }}=0.72 \pm 0.09 \mathrm{~m} \mathrm{~s}^{-1}$, and $V_{\text {cruising }}=$ $0.26 \pm 0.04 \mathrm{~m} \mathrm{~s}^{-1}$. All are within the range of the in situ observed swimming speeds shown in Hara (1987) and Misund et al. (2003). In the present study, the avoidance behavior shown against the TM9 and predator(s) was similar with regard to swimming speed and distance between the school and the instrument or predator. While there has been no quantitative study on sardines avoidance behavior against predators in the ocean, we speculate that the level of turbulence induced by sardines in the ocean is the same as that in this study.

During feeding, Japanese sardines exhibit 3 types of behavior in the ocean: filter-feeding, particulatefeeding, and intermediate mode (Garrido \& van der Lingen 2014). Filter-feeding is characterized by fish holding their mouths open while swimming without visual detection and selection, and particulate- feeding is characterized by visual detection and selection of individual prey (Garrido \& van der Lingen 2014). Sardine particulate-feed when prey size is larger than $1.23 \mathrm{~mm}$ (van der Lingen 1994). Since 2 $\mathrm{mm}$ diameter food pellets were fed to the sardines prior to the launching of Deployment 3, we suspect that they employed particulate-feeding behavior, given that it was not clear from the film footage which feeding behavior was employed. Garrido \& van der Lingen (2014) note that Japanese sardines appear to frequently filter-feed in the ocean, swimming slower than during particulate-feeding but faster than cruising speeds (Garrido et al. 2007).

During cruising, it was not possible to directly measure turbulence induced by this behavior. Since slower swimming speed may result in lower turbulent kinetic energy production (Huntley \& Zhou 2004; see 'Discussion: Dissipation rates'), the level of turbulence induced by cruising behavior is expected 

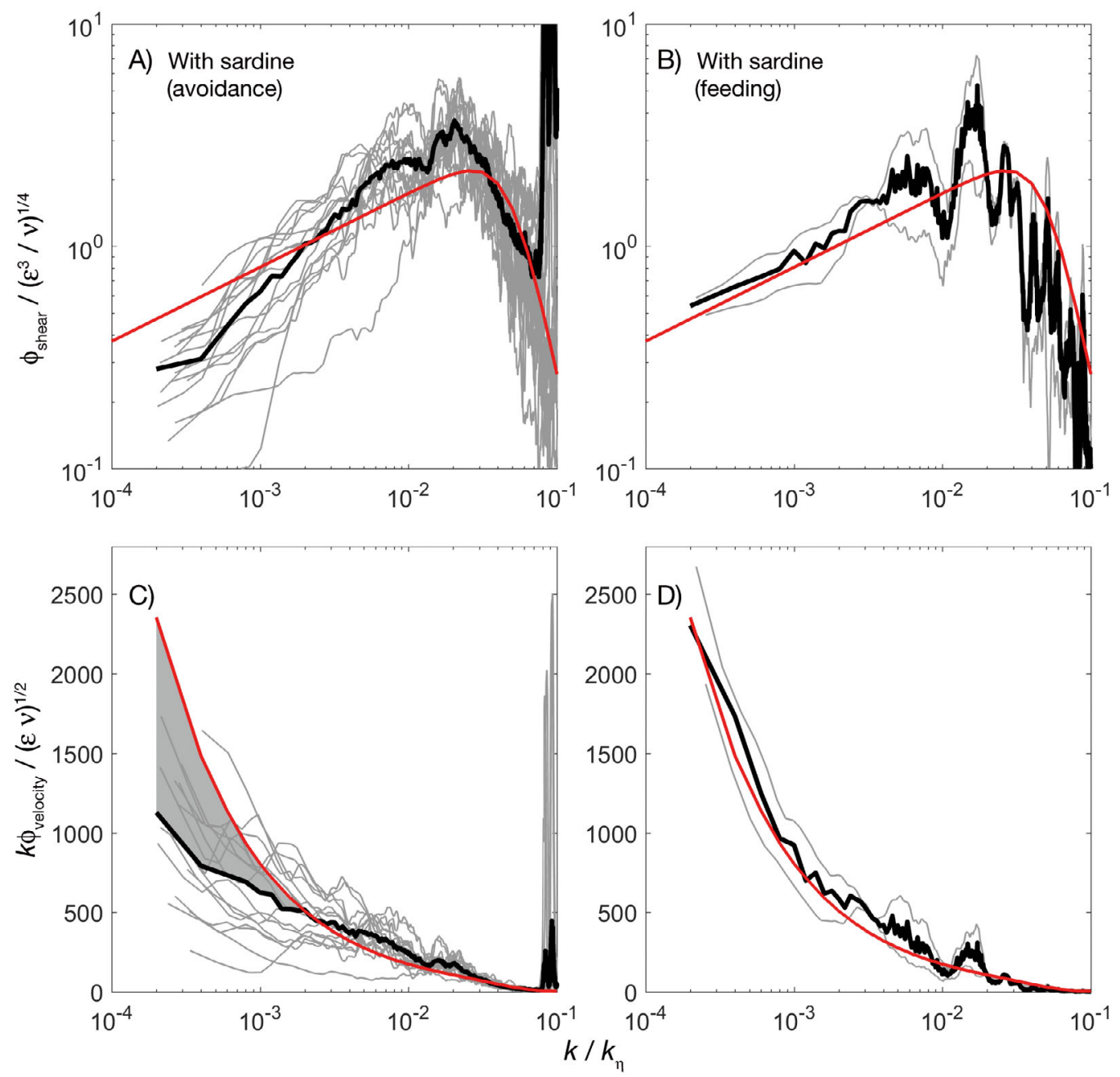

Fig. 7. $(A, B)$ Non-dimensionalized turbulent shear spectra $(\phi)$ using $\left(\varepsilon^{3} / v\right)^{1 / 4}$ as a function of non-dimensionalized wavenumber by Kolomogorov wavenumber $\left(k_{\eta}\right)$. $\varepsilon$ : turbulent kinetic energy dissipation rate, $v$ : kinematic viscosity. Raw spectra denoted by thin gray lines, averaged spectrum by thick black lines, and Nasmyth spectrum by red lines. (C,D) Variance-preserving forms of velocity spectra which are non-dimensionalized using $(\varepsilon v)^{1 / 2}$ as a function of non-dimensionalized wavenumber by Kolomogorov wavenumber. Area where averaged velocity spectrum is lower than the Nasmyth spectrum highlighted in light gray. (A,C) Data for sardine avoidance behavior include 16 spectra, and (B,D) data for feeding behavior include 2 spectra

to be lower than the measured turbulence intensity, $2.3 \times 10^{-4} \mathrm{~W} \mathrm{~kg}^{-1}$ on average. On the other hand, no difference in $\varepsilon$ between avoidance and feeding behaviors was obtserved (Table 1).

\section{Background turbulence}

Although the background turbulence of $10^{-6} \mathrm{~W}$ $\mathrm{kg}^{-1}$ measured in the tank is possible in the ocean, it occurs under limited situations, such as inside the surface mixed layer forced by winds (Oakey \& Elliott 1982) and surface cooling (Shay \& Gregg 1986) or in shallow regions under strong tidal forcing (Kokubu et al. 2013) or island wakes in strong ocean current regions (Hasegawa et al. 2004). In the interior of the open ocean, away from the boundaries, values of $\varepsilon$ vary from $10^{-10}$ to $10^{-7} \mathrm{~W} \mathrm{~kg}^{-1}$ and are generally in the order of $10^{-9}$ to $10^{-8} \mathrm{~W} \mathrm{~kg}^{-1}$ (Thorpe 2005). Since turbulent kinetic energy, which is newly input by a forcing source (e.g. internal wave breaking, shear instability) into the water column, is integrated on (added to) background turbulent kinetic energy (Nikora 1999), $\varepsilon$ of $10^{-4} \mathrm{~W} \mathrm{~kg}^{-1}$ acquired inside the sardine school may not be the net intensity of turbulence induced solely by the sardine school. However, since $\varepsilon$ inside the sardine school was 2 orders of magnitude higher than the background, bias due to background turbulence was negligible $(\sim 1 \%)$ in this study. 


\section{Dissipation rates}

The observed $\varepsilon$ caused by the sardine school was $2.3 \times 10^{-4} \mathrm{~W} \mathrm{~kg}^{-1}$ on average, which is among the largest values of past field studies (Hasegawa et al. 2004). Kunze et al. (2006) reported $\varepsilon=10^{-5}$ to $10^{-4} \mathrm{~W}$ $\mathrm{kg}^{-1}$ in krill aggregations in Saanich Inlet, Canada. On the other hand, Rousseau et al. (2010) noted $\varepsilon=$ $1.4 \times 10^{-8} \mathrm{~W} \mathrm{~kg}^{-1}$ with high acoustic backscatter intensity that was likely krill aggregations, in Saanich Inlet. Gregg \& Horne (2009) related $\varepsilon=10^{-6}$ to $10^{-5} \mathrm{~W} \mathrm{~kg}^{-1}$, with high acoustic backscatter intensity that was likely anchovy schools in Monterey Bay, USA. Lorke \& Probst (2010) reported $\varepsilon=3 \times 10^{-9}$ to $1 \times 10^{-8} \mathrm{~W} \mathrm{~kg}^{-1}$ based on fast response temperature sensor data in freshwater fish schools in Lake Constance, Germany. All the above studies used microstructure profilers similar to this study for measuring turbulence. Because the sardine school in this study displayed avoidance behavior against the microstructure profiler, it is possible that the results from the other studies might be due to avoidance behavior as well.

According to Huntley \& Zhou (2004), swimming organisms produce turbulence corresponding to $\varepsilon=$ $10^{-5} \mathrm{~W} \mathrm{~kg}^{-1}$ regardless of body size (from zooplankton to whales) using the equation:

$$
\varepsilon_{\mathrm{p}}=\frac{e_{d}}{\eta} \cdot \frac{1}{\rho} \cdot \frac{n}{V}
$$

where $\varepsilon_{\mathrm{p}}\left(\mathrm{W} \mathrm{kg}^{-1}\right)$ is the total rate of energy production by a group of animals, $e_{d}$ is the rate of energy expenditure to overcome drag by an individual animal, $\eta$ is propulsive efficiency, $\rho$ is density of seawater, and $n / V$ is the number of animals per unit volume of seawater. The $\varepsilon_{\mathrm{p}}$ is equivalent to $\varepsilon$ for swimming organisms, and $e_{d}$ and $\eta$ are functions of swimming speeds. While Huntley \& Zhou (2004) obtained $\varepsilon_{\mathrm{p}}=$ $10^{-5} \mathrm{~W} \mathrm{~kg}^{-1}$ based on only cruising speeds, we recalculated $\mathrm{e}_{d}$ and $\eta$ using the observed swimming speeds during avoidance behavior, $V_{\text {avoidance }}=1.08 \pm$ $0.11 \mathrm{~m} \mathrm{~s}^{-1}$ (mean $\pm \mathrm{SD}$ ), and feeding behavior, $v_{\text {feeding }}=0.72 \pm 0.09 \mathrm{~m} \mathrm{~s}^{-1}$ (see 'a. Calculation of $e_{d}$ and $\eta^{\prime}$ in the Supplement at www.int-res.com/ articles/suppl/m571p207_supp.pdf). Since we could not measure $n / V$ from the video footage, we estimated it based on the following assumptions: (1) the distribution of individual sardines in the school displayed hexagonal close-packing of equal spheres, and (2) the radius of the spheres was equal to the average body length $L=0.173 \mathrm{~m}$. The second assumption assumes that each sardine kept a distance of at least 1 body length from its neighbors. We obtained $n / V \sim 34.1$ individuals $\mathrm{m}^{-3}$ (see 'b. Estimation of $n / V^{\prime}$ in the Supplement), which seemed reasonable after comparing it with the footage. Seawater density $1 / \rho$ in Eq. (2) is canceled since $e_{d}$ is a linear function of $\rho$. Assuming possible ranges of the swimming speeds within $1 \mathrm{SD}$, the total rates of energy production are $\varepsilon_{\mathrm{p} \text { avoidance }}=(1.6$ to 2.7$) \times 10^{-3}$ $\mathrm{W} \mathrm{kg}{ }^{-1}$ for avoidance behavior and $\varepsilon_{\mathrm{p} \text { feeding }}=(5.3$ to 10.2) $\times 10^{-4} \mathrm{~W} \mathrm{~kg}^{-1}$ for feeding behavior. Thus, the estimated values from Huntley \& Zhou (2004) are an order of magnitude higher than the measured $\varepsilon=$ $(0.8$ to 5.2$) \times 10^{-4} \mathrm{~W} \mathrm{~kg}^{-1}$ in our experiment. Lorke \& Probst (2010) also reported that the estimated values of Huntley \& Zhou (2004) were higher than their measured turbulent kinetic energy dissipation rates.

\section{Spectrum shapes}

The spectra for avoidance and feeding behaviors showed deviations from the Nasmyth spectrum through all wavenumber ranges (Figs. 5 \& 6). This suggests that sardines successively generated turbulent eddies and continuously modified the turbulence field, unlike physically induced eddies. Since energycontaining scales in the ocean (e.g. thickness of surface mixed layer, internal wave height) are typically larger than the size of a microstructure profiler, the profilers can only measure eddy cascades and viscous dissipation processes in the ocean. On the other hand, the largest possible energy-containing eddies were formed at the scale similar to the sardine school size or the individual size $(L=0.173 \mathrm{~m})$ in this experiment. Although the spectra of the background turbulence followed the Nasmyth spectrum (Fig. 4), the spectra from the avoidance behavior showed power declines at wavenumber ranges lower than $L^{-1}=5.8 \mathrm{cpm}$ (Fig. 5). This suggests that the energy-containing scale was the same as or smaller than $L=0.173 \mathrm{~m}$ (Fig. 8A), since the kinetic energy of 3-D turbulent eddies cascades into smaller eddies (higher wavenumbers) (Nikora 1999). The power declines formed roughly $k^{+1}$ slopes in the inertial sub-range, consistent with Gregg \& Horne (2009), and was similar to that found in the turbulence field inside the bottom boundary layer where turbulent eddies are successively generated as a result of flow instability (Nikora 1999).

The spectra from the feeding behavior did not show power declines at wavenumber ranges lower than $L^{-1}=5.8 \mathrm{cpm}$ (Fig. 6). Although only a single turbulence microstructure profile was made during feeding behavior, spectral shapes obtained simultaneously by 2 turbulent shear probes indicate that 


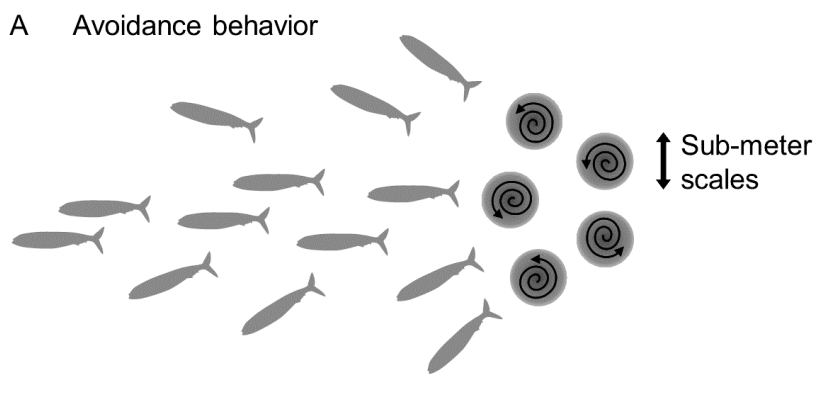

B Feeding behavior

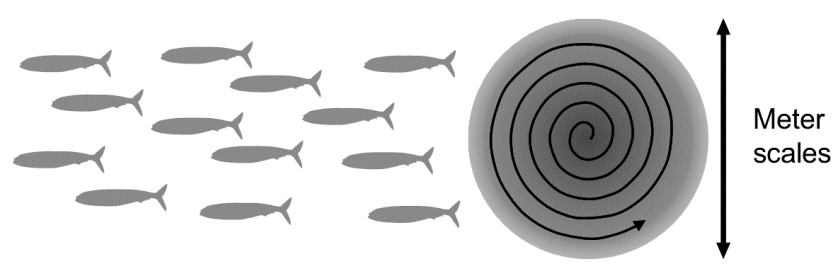

Fig. 8. Relationship between fish school behavior and size of school-generated turbulent eddy. (A) Turbulent eddies generated by a school displaying a quick and non-continuous motion, such as avoidance behavior, have the same size as individual body size. (B) Turbulent eddies generated by a school displaying a fast and long-lasting motion, such as particulate-feeding, have the same size as the school

there was no power decline even in the inertial subrange. This suggests that the energy-containing scale was the same as or larger than the school thickness of $\sim 1 \mathrm{~m}$ (Fig. 8B, Table 1). On the other hand, there was a discrepancy between the spectra (Fig. 6A,B), which clearly shows that the flow field was not isotropic. This anisotropic turbulence may be caused by the anisotropic swimming pattern produced by the feeding school.

Catton et al. (2011) conducted a small tank experiment to study fluid motion around swimming krill using laser sheet illumination. They reported that krill aggregations actively transferred water parcels down to successive group members, consequently disturbing the water column at a scale of aggregations. Although fluid motions around krill and sardines are different, we speculate that the sardines' synchronous long-lasting group motions generate turbulent eddies larger than their individual body size (Fig. 8B).

\section{Mixing efficiency and eddy diffusivity}

Based on results from the nearly homogeneous tank experiment, which suggest that sardines are able to generate eddies as large as their school size and as small as their body size, and assuming that these results are applicable in the stratified ocean, we estimate plausible values of the efficiency factor $\Gamma$ and vertical eddy diffusivity of density $K_{\rho}$ in the ocean, where $\Gamma$ is a ratio between buoyancy destruction rate and turbulent kinetic energy dissipation rate, and is generally upperbounded by $\Gamma=0.2$ (Osborn 1980). Visser (2007) pointed out that when $\Gamma$ is low, turbulence scarcely contributes to mixing even if turbulent kinetic energy dissipation rates are high. He estimated that $\Gamma$ does not exceed 0.01 , when turbulence is generated by an individual small swimmer $(\sim 1 \mathrm{~cm})$. However, his assumption does not take into account the effects of group motions, which can be effective as indicated by Catton et al. (2011) and this study. Following the model by Osborn (1980), $K_{\rho}$ is expressed as:

$$
K_{\rho}=\Gamma \frac{\varepsilon}{N^{2}}
$$

where $N$ is the buoyancy frequency. Smyth et al. (2001) showed that $\Gamma$ may be approximated as:

$$
\Gamma \sim 0.33\left(\frac{L_{T}}{L_{O}}\right)^{0.63}
$$

where $L_{T}$ is the Thorpe scale, representing an overturning scale, and $L_{O}$ is the Ozmidov scale, $L_{O}=(\varepsilon /$ $\left.N^{3}\right)^{1 / 2}$, which is the largest turbulent eddy size in a stratified water column. Measured $\varepsilon$ caused by the sardine school varied between $8.2 \times 10^{-5}$ and $5.2 \times$ $10^{-4} \mathrm{~W} \mathrm{~kg}^{-1}$. Generally, $N=1 \times 10^{-2}$ to $3 \times 10^{-2} \mathrm{~s}^{-1}$ in the stratified ocean (Thorpe 2007). Based on our results, the overturning scale by sardines is as small as their individual body size, and as large as their school thickness (Fig. 8). First, we assume that the overturning scale is similar to the thickness of the school, $L_{T} \sim$ $1 \mathrm{~m}$ (Fig. 8B). Using all ranges of $\varepsilon$ and $N$, we obtain $\Gamma=0.05$ to 0.23 and $K_{\rho}=2.1 \times 10^{-2}$ to $2.4 \times 10^{-1} \mathrm{~m}^{2} \mathrm{~s}^{-1}$. The estimated $\Gamma$ can reach $\Gamma=0.2$, as in Osborn (1980). On the other hand, when the overturning scale is assumed to be individual body size $L_{T} \sim L=$ $0.173 \mathrm{~m}$ (Fig. 8A), we obtain $\Gamma=0.02$ to 0.08 and $K_{\rho}=$ $7.0 \times 10^{-3}$ to $7.9 \times 10^{-2} \mathrm{~m}^{2} \mathrm{~s}^{-1}$. The estimated $\Gamma$ is in a range consistent with Visser (2007). Regardless of the assumptions of $L_{T}$, the estimated $K_{\rho}$ range is noticeably high when compared with $K_{\rho}=10^{-4}$ to $10^{-3} \mathrm{~m}^{2}$ $\mathrm{s}^{-1}$ measured in a highly tidally mixed channel (e.g. Kokubu et al. 2013). These rough estimates of mixing efficiency and diffusivities are based on the assumption that the sardine school can generate large energy-containing eddies in a stratified ocean, the same as that in the nearly homogeneous tank exper- 
iment. Note, however, that because stratification can support internal waves and suppress turbulent eddies, the scale of the eddies could be smaller than that found in this study.

\section{Implications of large-scale mixing}

While the results from this study contain uncertainty due to the small number of samples, we provide a rough estimate of sardine impact on ocean mixing at scales of local seas. We consider a case off the west coast of the United States where mixing processes and sardine biomass are well studied. We assume that the results from our study are applicable to Pacific sardine Sardinops sagax, whose characteristics such as body shape, body length, and wet weight, are similar to $S$. melanostictus (Whitehead 1985). The estimated biomass of $S$. sagax off the west coast of the USA is roughly 1 million $t$, where the area under consideration is $400000 \mathrm{~km}^{2}$, and standard length and wet weight of the sardine are $0.20 \mathrm{~m}$ and $0.10 \mathrm{~kg}$ on average (Hill et al. 2014). Based on average wet weight and estimated biomass, the population abundance is roughly $10^{10}$ individuals. We now assume that all the individuals form schools whose dimensions are roughly 100 to $300 \mathrm{~m}^{2}$ in area and 5 to $10 \mathrm{~m}$ in height for each school (Castillo \& Robotham 2004), and that the distribution of the individuals form hexagonal close-packing of equal spheres, whose radius is equal to the average body length $\mathrm{r} \sim$ $0.20 \mathrm{~m}$ (see Eqs. S4 \& S5 in the Supplement): the population density is approximately 22.1 ind. $\mathrm{m}^{-3}$. Dividing population abundance by population density, the total volume of the schools is $4.5 \times 10^{8} \mathrm{~m}^{3}$, which can be converted to mass by multiplying typical seawater density in the upper $100 \mathrm{~m}$ in the ocean, $1028 \mathrm{~kg} \mathrm{~m}^{-3}$ (Thorpe 2005). Thus, the total water mass that the schools occupy is $4.7 \times 10^{11} \mathrm{~kg}$. Multiplying the total water mass by turbulent kinetic energy dissipation rates with a range of $\varepsilon \sim$ $10^{-5}$ to $10^{-4} \mathrm{~W} \mathrm{~kg}^{-1}$, where we use a lower limit as reported by Gregg \& Horne (2009) and an upper limit as measured in this study, the total kinetic energy dissipation is 4.7 to $47.0 \mathrm{MW}$. This estimation is comparable with or higher than the kinetic energy dissipation of 8.3 MW generated by internal wave breaking in the Monterey Canyon (Jachec et al. 2006), where diapycnal turbulent mixing actively occurs (Kunze et al. 2002). Therefore, biomixing may not be negligible in certain parts of the world ocean.

\section{CONCLUSION}

We successfully collected microstructure data from inside a school of Japanese sardines Sardinops melanostictus in an aquarium tank where we were able to 'watch' sequences of biomixing. The average turbulent kinetic energy dissipation rate inside the school was $\varepsilon=2.3 \times 10^{-4} \mathrm{~W} \mathrm{~kg}^{-1}$, while $\varepsilon=6.7 \times 10^{-6} \mathrm{~W} \mathrm{~kg}^{-1}$ was the average background value outside the school. Our experiment using video cameras first revealed that the fishes exhibited avoidance behavior to the approaching microstructure profiler, suggesting that it is very challenging to measure true biologically induced turbulence without any artificial influences. Most of the turbulence measurements inside the sardine school were the result of the fish undergoing short bursts of speed in an effort to avoid the oncoming profiler. On the other hand, the school exhibited relatively fast and long-lasting synchronized swimming when they were being fed. Here, their swimming behavior was dominated by feeding motions, whereas the school manifested avoidance behavior in regard to the profiler, keeping about $1 \mathrm{~m}$ from the instrument. Turbulent shear spectra for the avoidance behavior showed a power decline in the lower $\left(<L^{-1}\right)$ wavenumber ranges against the Nasmyth spectrum, consistent with Gregg \& Horne (2009), while spectra for the feeding behavior exhibited no power decline, similar to physically induced turbulence. For the avoidance case, the largest scale of turbulent kinetic energy that the sardine could produce was roughly its individual body size $L$, consistent with Visser (2007). On the other hand, the largest scale was at least $1 \mathrm{~m}$, as large as the sardine school thickness of approximately $1 \mathrm{~m}$, for the feeding case. However, at the level of turbulent kinetic energy dissipation rates, there was no noticeable difference between avoidance behavior and feeding behavior. Although the results from this study contain some uncertainty due to the small number of deployments, the data clearly show that fish schools are able to generate turbulent eddies as large as their school thickness and cause efficient turbulent mixing similar to naturally occurring turbulence.

Acknowledgements. We are indebted to Yokohama Hakkeijima Inc. for allowing us to use their tank. We thank Yuki Omata and Sou Abe at Yokohama Hakkeijima Inc. for collecting the sardines and for helping to keep the experiment running smoothly. We thank Alexander Vitek, Kiyomi Baerg, Lynn Allmon and Rosalie Rutka for their assistance in the preparation of the manuscript and all colleagues who volunteered to conduct the experiment. A partial fund for this work was supported by JST CREST Grant Number JPMJCR12A6. 


\section{LITERATURE CITED}

Castillo J, Robotham H (2004) Spatial structure and geometry of schools of sardine (Sardinops sagax) in relation to abundance, fishing effort, and catch in northern Chile. ICES J Mar Sci 61:1113-1119

Catton KB, Webster DR, Kawaguchi S, Yen J (2011) The hydrodynamic disturbances of two species of krill: implications for aggregation structure. J Exp Biol 214: 1845-1856

Dewar WK, Bingham RJ, Iverson RL, Nowacek DP, St. Laurent LC, Wiebe PH (2006) Does the marine biosphere mix the ocean? J Mar Res 64:541-561

Ferrari R, Wunsch C (2009) Ocean circulation kinetic energy: reservoirs, sources, and sinks. Annu Rev Fluid Mech 41:253-282

Garrido S, van der Lingen CD (2014) Feeding biology and ecology. In: Ganias K (ed) Biology and ecology of sardines and anchovies. CRC Press, Boca Raton, FL, p 122-189

Garrido S, Marçalo SA, Zwolinski J, van der Lingen CD (2007) Laboratory investigations on the effect of prey size and concentration on the feeding behaviour of Sardina pilchardus. Mar Ecol Prog Ser 330:189-199

Gregg MC, Horne JK (2009) Turbulence, acoustic backscatter, and pelagic nekton in Monterey Bay. J Phys Oceanogr 39:1097-1114

Hara I (1987) Swimming speed of sardine school on the basis of aerial survey. Bull Jpn Soc Sci Fish 53:223-227

Hasegawa D, Yamazaki H, Lueck RG, Seuront L (2004) How islands stir and fertilize the upper ocean. Geophys Res Lett 31:L16303

Hill KT, Crone PR, Demer DA, Zwolinski J, Dorval E, Macewicz BJ (2014) Assessment of the Pacific sardine resource in 2014 for USA management in 2014-15. NOAA Tech Memo NMFS-SWFSC-531. Southwest Fisheries Science Center, NOAA, La Jolla, CA

Huntley ME, Zhou M (2004) Influence of animals on turbulence in the sea. Mar Ecol Prog Ser 273:65-79

Jachec SM, Fringer OB, Gerritsen MG, Street RL (2006) Numerical simulation of internal tides and the resulting energetics within Monterey Bay and the surrounding area. Geophys Res Lett 33:L12605

Katija K, Dabiri JO (2009) A viscosity-enhanced mechanism for biogenic ocean mixing. Nature 460:624-626

Kokubu Y, Yamazaki H, Nagai T, Gross ES (2013) Mixing observations at a constricted channel of a semi-closed estuary: Tokyo Bay. Cont Shelf Res 69:1-16

Kunze E, Rosenfeld LK, Carter GS, Gregg MC (2002) Internal waves in Monterey Submarine Canyon. J Phys Oceanogr 32:1890-1913

Editorial responsibility: Alejandro Gallego, Aberdeen, UK
Kunze E, Dower JF, Beveridge I, Dewey R, Bartlett KP (2006) Observations of biologically generated turbulence in a coastal inlet. Science 313:1768-1770

光Lorke A, Probst WN (2010) In situ measurements of turbulence in fish shoals. Limnol Oceanogr 55:354-364

* Misund OA, Coetzee JC, Fréon P, Gardener M, Olsen K, Svellingen I, Hampton I (2003) Schooling behavior of sardine Sardinops sagax in False Bay, South Africa. Afr J Mar Sci 25:185-193

Nikora V (1999) Origin of the '-1' spectral law in wallbounded turbulence. Phys Rev Lett 83:734-736

Oakey NS (1982) Determination of the rate of dissipation of turbulent energy from simultaneous temperature and velocity shear microstructure measurements. J Phys Oceanogr 12:256-271

Oakey NS, Elliott JA (1982) Dissipation within the surface mixed layer. J Phys Oceanogr 12:171-185

Osborn TR (1980) Estimates of the local rate of vertical diffusion from dissipation measurements. J Phys Oceanogr 10:83-89

Ross T, Lueck R (2005) Estimating turbulent dissipation rates from acoustic backscatter. Deep Sea Res I 52:2353-2365

* Rousseau S, Kunze E, Dewey R, Bartlett K, Dower J (2010) On turbulence production by swimming marine organisms in the open ocean and coastal waters. J Phys Oceanogr 40:2107-2121

Saita T, Shiki S, Tai A, Shigeta S, Yano S, Komatsu T (2009) Evaluation of vertical mixing by in situ measurements off the coast of Shimabara Peninsula. JSCE Proc Hydraul Eng 53:1471-1476

Sato M, Klymak JK, Kunze E, Dewey R, Dower JF (2014) Turbulence and internal waves in Patricia Bay, Saanich Inlet, British Columbia. Cont Shelf Res 85:153-167

Shay TJ, Gregg MC (1986) Convectively driven turbulent mixing in the upper ocean. J Phys Oceanogr 16:1777-1798

Smyth WD, Moum JN, Caldwell DR (2001) The efficiency of mixing in turbulent patches: inferences from direct simulations and microstructure observations. J Phys Oceanogr 31:1969-1992

Thorpe SA (2005) The turbulent ocean. Cambridge University Press, Cambridge

Thorpe SA (2007) An introduction to ocean turbulence. Cambridge University Press, Cambridge

*van der Lingen CD (1994) Effect of particle size and concentration of the feeding behavior of adult pilchard Sardinops sagax. Mar Ecol Prog Ser 109:1-13

*Visser AW (2007) Biomixing of the oceans? Science 316: 838-839

Whitehead PJP (1985) Clupeoid fishes of the world. I. Chirocentridae, Clupeidae and Pristigasteridae. FAO, Rome

Submitted: July 29, 2016; Accepted: February 17, 2017 Proofs received from author(s): April 7, 2017 